Revista Mídia e Cotidiano

ISSN: 2178-602X

Artigo Seção Temática

Volume 15, Número 2, maio/ago. de 2021

Submetido em: 07/02/2021

Aprovado em: 05/04/2021

\title{
Deslocamentos de visibilidades hegemônicas e diálogos entre representações da cozinha no reality show Cook Off - Duelo de Sabores
}

\section{Displacements of hegemonic visibilities and dialogues between representations of cuisine on the reality show Cook Off - Duelo de Sabores}

Desplazamientos de visibilidades hegemónicas y diálogos entre representaciones de la cocina en el reality show Cook Off-Duelo de Sabores

\author{
Nara Lya Cabral SCABIN ${ }^{1}$
}

\begin{abstract}
Resumo
$\mathrm{O}$ artigo busca compreender as maneiras pelas quais diálogos com/entre regimes representacionais da cozinha inscrevem-se no reality show Cook Off - Duelo de Sabores, exibido em 2015 pela emissora televisiva portuguesa RTP1. Ao mesmo tempo, evidencia como a produção mobiliza e, sobretudo, tensiona visibilidades hegemônicas do gênero reality show. Nesse percurso, identificam-se tensionamentos relativos tanto aos enquadramentos da temática da competição quanto às representações do que denominamos uma "cozinha como culinária". Quanto ao segundo ponto, não obstante o olhar gastronomizado dos chefs assuma uma posição hierarquicamente destacada, o programa dá a ver imagens que evidenciam o (re)conhecimento de uma cozinha cotidiana e popular, nas quais se entreveem "artes de fazer" do dia a dia.
\end{abstract}

Palavras-chave: Reality show. Culinária. Gastronomia. Dialogismo. Representações.

\begin{abstract}
The article seeks to understand the ways in which dialogues with/between representational regimes about cookery are included in the reality show Cook Off-Duelo de Sabores, shown in 2015 by the Portuguese television station RTP1. At the same time, it shows how the production mobilizes and, above all, tensions hegemonic visibilities of the reality show genre. Along this path, we identify tensions related to both the framing of the competition theme and the representations of what we call "cookery as culinary". Regarding the second point, despite the gastronomized view of cuisine chefs takes a
\end{abstract}

\footnotetext{
1 Professora do Programa de Pós-Graduação em Comunicação da Universidade Anhembi Morumbi (PPGCOM-UAM) e pós-doutoranda em Comunicação e Práticas de Consumo pela Escola Superior de Propaganda e Marketing (ESPM). E-mail: naralyacabral@yahoo.com.br. ORCID: 0000-0002-71211142.
} 
highlighted position, the program presents images that recognize a daily and popular cuisine, in which we can see "arts of making" from day-to-day.

Keywords: Reality show. Culinary. Gastronomy. Dialogism. Representations.

\section{Resumen}

El artículo busca comprender las formas en que los diálogos con/entre los regímenes representacionales de la cocina se incluyen en el reality show Cook Off - Duelo de Sabores, presentado en 2015 por la cadena de televisión portuguesa RTP1. Al mismo tiempo, muestra cómo la producción moviliza y, sobre todo, desplaza visibilidades hegemónicas del género reality show. En este camino se identifican tensiones relacionadas tanto con el encuadre del tema de la competitividad como con las representaciones de lo que llamamos "cocina como culinaria". En cuanto al segundo punto, a pesar de la mirada gastronomizada de los chefs asuma una posición jerárquicamente destacada, el programa presenta imágenes de (re)conocimiento de una cocina cotidiana y popular, en las que se muestran "artes de hacer" del día a día.

Palabras clave: Reality show. Culinaria. Gastronomía. Dialogismo. Representaciones.

\section{Introdução}

Se, com a história da alimentação, aprendemos que comida é expressão cultural materializada em modos de produção dos ingredientes, técnicas de preparo e rituais de consumo (MONTANARI, 2008), não é preciso mais do que um rápido passeio pela programação televisiva para constatar o destaque adquirido por produtos voltados ao entretenimento alimentar na cultura midiática contemporânea.

A popularidade conquistada por tais produções deve ser considerada à luz de um quadro mais amplo de expansão da visibilidade conferida à comida na cultura midiática, acompanhando o surgimento de práticas de consumo articuladas em torno da valorização de alimentos gourmet, da disseminação de cursos e escolas de gastronomia, da fama conquistada por chefs e seus restaurantes junto a públicos de elevado poder aquisitivo. Com isso, assistimos à emergência de novos regimes de visualidade midiática da culinária e da gastronomia, os quais se relacionam a uma verdadeira "onda de consumo do universo da cozinha" (OLIVEIRA, 2016, p. 136).

Nesse contexto, destacam-se, em termos de índices audiência e visibilidade, títulos que levam para a tela da TV competições em torno de desafios culinários/gastronômicos. São, em geral, programas que mobilizam aspectos 
característicos de reality shows - como a superação de obstáculos em situações de estresse e competitividade -, muitas vezes hibridizados com elementos próprios de outros gêneros e formatos televisivos. É o caso de Cook Off - Duelo de Sabores, exibido entre maio e outubro de 2015 pela emissora portuguesa RTP, um caso típico de reality show de competição culinária/gastronômica no qual comparecem também elementos de programas com foco em turismo gastronômico ${ }^{2}$.

Exibida no horário nobre do Canal 1 aos domingos, a produção foi vista, em seu episódio final, por mais de 446 mil espectadores e alcançou 9,7 de share $^{3}$. Os índices ficaram aquém daqueles registrados na estreia do programa $(6,1 \%$ de rating e $12,7 \%$ de share), dado que pode ser atribuído ao fato de as transmissões terem sido pausadas durante o verão por decisão do diretor Daniel Deusdados ${ }^{4}$. Houve semanas, porém, em que Cook Off chegou a 7,7\% de rating e $16,6 \%$ de share $^{5}$. Não se trata de números pouco expressivos, sobretudo quando se consideram os índices da RTP1 em 2015, quando a emissora foi a terceira preferida pelos portugueses entre canais generalistas ${ }^{6}$.

Do ponto de vista narrativo, o programa mostra, ao longo de 13 episódios, a saga de dois chefs de cozinha - chef Cordeiro e chef Kiko - em busca dos "melhores sabores de Portugal". Com apresentação de Catarina Furtado, eles visitam a cada capítulo duas regiões portuguesas, onde montam equipes formadas por habitantes locais, todos cozinheiros amadores, que se enfrentam no último bloco do programa, devendo preparar pratos representativos da cozinha de cada localidade. Dessa forma, Cook Off - Duelo de Sabores mobiliza um tom celebrativo da diversidade de culinárias regionais e, por

\footnotetext{
${ }^{2}$ Se optarmos por enquadrar o programa em propostas tipológicas mais específicas, como a desenvolvida por Rezende e Lavinas (2017), por exemplo, chegaremos a uma categorização correlata: dentre as tipologias descritas pelas autoras, Cook Off - Duelo de Sabores é um caso de "reality show" que explora também elementos do enquadramento "antropológico/exótico", cujo objetivo básico é a expansão da territorialidade e a experimentação de diferentes práticas alimentares.

${ }^{3}$ Informações disponíveis em: https://www.atelevisao.com/rtp/final-de-cook-off-duelo-de-sabores-vistapor-445-mil/. Acesso em: 13 jan. 2021.

4 Informações disponíveis em: https://www.zapping-tv.com/rtp1-suspende-cook-off-duelo-de-saboresdurante-o-verao/. Acesso em: 13 jan. 2021.

${ }^{5}$ Informações disponíveis em: https://diario-da-tv.blogspot.com/2015/06/cook-off-tem-melhor-resultadoe-idolos.html. Acesso em: 13 jan. 2021.

${ }^{6}$ Segundo dados divulgados pelo Diário de Notícias, em 2015, a RTP1 registrou média de 14,8\% de share em 2015, contra 15,6\% no ano anterior (COSTA, 2016).
} 
conseguinte, da riqueza da cozinha nacional portuguesa, como evidencia a descrição disponível no site da RTP:

O objetivo é colocarem Portugal a cozinhar e revelar o que se cozinha de melhor nas suas regiões, para que numa prova final se apure a região com os melhores cozinheiros. No programa final vamos eleger a região mais saborosa de Portugal.

Ao longo dos programas, mantendo uma saudável competição gastronómica, os chefes e as suas equipas vão dar-nos a conhecer o melhor de cada região, no que toca a gastronomia, tradições e histórias locais (RTP, s./d., online).

Com essa proposta, o programa mostra-se representativo das negociações estabelecidas entre sentidos de uma cozinha como gastronomia e sentidos de uma cozinha como culinária que parecem caracterizar os enquadramentos da comida, do comer e do cozinhar na cultura midiática contemporânea. Segundo Jacob (2012), é possível pensar gastronomia e culinária como duas "linguagens" distintas e, ao mesmo tempo, interconectadas, por meio das quais a alimentação se comunica.

Assim, por "cozinha como gastronomia", referimo-nos às representações da cozinha dos chefs, dos grandes restaurantes, do saber de especialistas, ou seja, representações uma cozinha de algum modo mediada por estratégias de legitimação próprias do campo gastronômico. Já por “cozinha como culinária”, referimo-nos às representações da cozinha cotidiana, familiar, popular, tradicional, predominantemente feminina etc., ou seja, uma cozinha que de algum modo prescindiria, ao menos em princípio, das estratégias de legitimação frequentes no campo gastronômico ${ }^{7}$. Longe de constituírem regimes representacionais estanques, os sentidos de cozinha como culinária e de cozinha como gastronomia negociam-se e delimitam-se mutuamente a cada vez que são (re)atualizados e postos em diálogo nas audiovisualidades contemporâneas.

\footnotetext{
${ }^{7}$ Convém observar que, no âmbito das práticas sociais, não é possível dissociar plenamente as esferas da culinária - "a arte de saber comer e cozinhar" - e da gastronomia - processo historicamente inscrito de valorização, legitimação ou estetização da culinária (JACOB, 2012) -, já que o domínio gastronômico, entendido como campo institucional e economicamente estruturado, cada vez mais engloba e ressignifica a produção e o consumo alimentares. Dessa forma, a distinção entre cozinha como gastronomia e cozinha como culinária se apresenta como ferramenta analítica baseada em tipos ideais que remetem ao assentamento de imaginários sociais e construções discursivas (re)elaboradas no plano da representação.
} 
Partindo dessa distinção, propomos analisar as maneiras pelas quais os diálogos com/entre diferentes regimes representacionais da cozinha inscrevem-se na materialidade discursiva do programa $^{8}$, regendo a produção das visualidades nele engendradas. Guiamnos proposições do Círculo de Bakhtin, com destaque para o princípio do dialogismo discursivo, tal como postulado no trabalho de Volóchinov (2017), conceito que nos permite cotejar a hipótese de que o diálogo com diferentes sentidos em circulação acerca da cozinha e suas práticas é constitutivo da própria textualidade audiovisual da produção em foco. Assim, não obstante a existência de diferentes abordagens da noção de dialogismo, privilegiamos aquela que se refere ao "diálogo entre os muitos textos da cultura, que se instala no interior de cada texto e o define" (BARROS, 2003, p. 4).

Nesse percurso, considerando o papel que os gêneros discursivos desempenham na comunicação em diferentes campos da atividade humana, com base em Bakhtin (2016), esperamos também discutir de que modo Cook Off - Duelo de Sabores mobiliza e, sobretudo, tensiona convenções e visibilidades hegemônicas do gênero reality show. Trata-se de tensionamentos, como veremos, que se mostram intimamente ligados ao lugar que os diálogos estabelecidos com sentidos de cozinha como culinária ocupam na produção.

\section{Entre convenções genéricas e visibilidades tensionadas}

Embora ocupem espaços destacados em emissoras por assinatura, programas culinários/gastronômicos também têm conquistado audiências na TV aberta. Neste espaço, o interesse dos espectadores parece voltar-se, sobretudo, a produções que apresentam competições de cozinha, nas quais é frequente a mobilização de características próprias do gênero do discurso televisivo conhecido como reality show.

\footnotetext{
${ }^{8}$ Fundamental às reflexões desenvolvidas neste trabalho, o conceito de representação será aqui tomado em perspectiva discursiva, considerando sua inextrincável imbricação com o engendramento de subjetividades. Destacamos, especialmente, o fato de as representações, em sua manifestação discursiva, serem responsáveis pela visibilização das posições-de-sujeito possíveis a um tempo e lugar. Nesse sentido, a perspectiva Stuart Hall (2016) nos é particularmente cara.
} 
Com base na distinção proposta por Keane e Moran (2008) ${ }^{9}$, empregamos, neste trabalho, o conceito de "gênero" (em lugar de "formato"), a fim de ressaltar justamente os aspectos narrativos/discursivos do reality show. No mesmo sentido, filiamo-nos à perspectiva de Bakhtin (2016), para quem os gêneros discursivos são modelos enunciativos estabilizados, profundamente ligados à dimensão das práticas sociais. Em torno dos gêneros, articulam-se convenções determinadas pelas especificidades de cada campo de comunicação, as quais se manifestam em diferentes aspectos - conteúdo temático, estilo, construção composicional - "indissoluvelmente ligados no conjunto do enunciado" (BAKHTIN, 2016, p. 12). Assim, a proposta bakhtiniana dialoga com a concepção desenvolvida por Martín-Barbero (2003), autor segundo o qual os gêneros devem ser vistos como modelos de sociabilidade e devem constituir a unidade de análise prioritária da cultura de massas. Essa visão ecoa ainda nas palavras de François Jost (2007), para quem os gêneros televisivos são convenções que operam condensando e organizando expectativas do público acerca da produção no campo da TV.

Não objetivamos aqui traçar um amplo histórico do reality show como gênero do discurso televisivo, assim como foge à proposta do trabalho uma recuperação exaustiva dos debates teórico-conceituais em torno de suas características. Não obstante, a fim de ser possível compreender de que maneira Cook Off - Duelo de Sabores articulase a partir de negociações em torno de representações recorrentes em produções filiadas a convenções típicas do reality show, faz-se necessário resgatar parte da discussão acadêmica sobre o gênero em questão. Dessa forma, a partir do estudo de um caso singular, esperamos contribuir também à discussão sobre o estatuto do reality show de competição culinária/gastronômica ${ }^{10}$, enfatizando especialmente as possibilidades de

\footnotetext{
9 Enquanto a concepção de "gênero", conforme destacada pelos autores, ressalta o caráter socialmente estabelecido das convenções genéricas, o "formato" diz respeito a modos de produção e modelos de negócio. Dessa forma, pode-se falar na transformação de gêneros televisivos, como o reality show, em formatos transnacionais, que comportam franquias exportadas para diferentes países.

10 Optamos aqui pela denominação de reality shows "culinários/gastronômicos" (ou reality shows de competição "culinária/gastronômica") por diferentes motivos: em primeiro lugar, em função da diversidade de nomenclaturas adotadas em trabalhos sobre o tema, que ora referem-se a tais produções como "culinárias", ora como "gastronômicas"; em segundo lugar, a escolha se justifica como forma de evitar as armadilhas conceituais decorrentes de tomadas imprecisas dos termos envolvidos, já que, como consideramos, como já dissemos, culinária e gastronomia são elementos articuladores de diferentes regimes representacionais sobre a cozinha.
} 


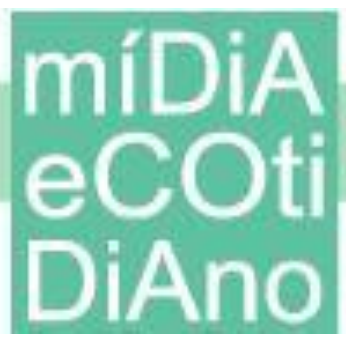

tensionamento e resistência em relação a visibilidades hegemonicamente elaboradas nesse tipo de produção televisiva.

O reality show constitui a manifestação por excelência do fenômeno da reality $T V$, uma variedade da programação popular factual que envolve a exploração de diferentes técnicas e estilos - tais como escalação de atores não profissionais, imagens de câmeras de vigilância e diálogos não roteirizados, por exemplo - com o objetivo de representar eventos como se eles estivessem ocorrendo "em frente às câmeras" (HILL, 2007). Com efeito, tem-se uma "referencialização" da produção televisiva como um todo a partir do empenho em tornar as produções cada vez mais "reais":

O que caracteriza um programa ou quadro televisivo como reality $T V$ não é propriamente o seu formato, mas a utilização de elementos de linguagem que enfatizam o referente e geram simulações que aproximam a ficção e a realidade. [...] Enquanto outros modos de fazer TV admitem limites entre o mundo vivido e o mundo midiático, a reality $T V$ procura eliminá-los (ROCHA, 2009, p. 3).

Criado por esse modo de fazer televisão e integralmente pautado por sua lógica de funcionamento, o reality show é descrito, por Aronchi de Souza (2004), como ligado a uma rearticulação do voyeurismo no século XXI pelo prazer de observar a intimidade de outras pessoas. No caso de realities de gastronomia/culinária, um traço marcante, segundo Rezende e Lavinas (2017), é o fato de a comida ser posta a serviço do espetáculo e converter-se em ferramenta de entretenimento. Considerando o reality show como uma tipologia para classificar a programação televisiva com temáticas ligadas à cozinha, as autoras apontam que, nessa classe de produção,

[...] a comunicação é realizada pelos chefs de cuisine "da vida real", considerados celebridades midiáticas, os quais se encarregam de conduzir, na maior parte das vezes, produções audiovisuais em competições ou jogos, relacionando conceitos diversos, entre eles, sofisticação, criatividade, estética e performance, às práticas alimentares (REZENDE; LAVINAS, 2017, p. 78).

Em Cook Off - Duelo de Sabores, vemos a materialização de parte das características descritas pelas autoras. Isso porque, por um lado, o programa propõe competições culinárias entre equipes de diferentes regiões de Portugal, das quais 
participam cozinheiros anônimos, escolhidos, entre moradores locais desconhecidos do público, por chefs-celebridades da "vida real". Por outro lado, ainda que a presença de reconhecidos chefs constitua um elemento narrativo fundamental, sua função parece ser antes a de revelar sabores locais pelas mãos de cozinheiros que se mostram tributários de práticas cotidianas e saberes populares, em um estreito diálogo com sentidos do que temos chamado de cozinha como culinária. Em outras palavras, sentidos relacionados a representações de uma cozinha como gastronomia, elencados por Rezende e Lavinas (2017) como elementos característicos de reality shows gastronômicos/culinários, têm importância, se não menos decisiva, ao menos não exclusiva em Cook Off.

Ao mesmo tempo, já à primeira vista é possível identificar no programa traços estilísticos que o aproximam de algumas das convenções mais características do reality show, inclusive em sua vertente culinária/gastronômica.

Enquanto narrativa midiática, estes programas utilizam-se do valor da experiência vivida, "próxima ao real", traçando um certo pacto de autenticidade e veracidade com os espectadores. É como se presenciássemos na tela o que acontece do lado de fora dela [...] (REZENDE, LAVINAS, 2017, p. 87).

A busca por autenticidade em Cook Off revela-se principalmente na montagem dos episódios. É o caso do modo como são apresentadas declarações de participantes do programa, que falam olhando diretamente para a câmera, como forma de dirigirem-se aos espectadores (ver Figura 1), em uma clara manifestação de "simulação do improviso" (REZENDE, LAVINAS, 2017, p. 86). 


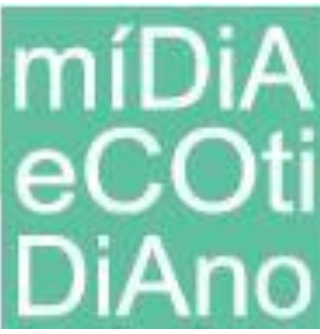

PPGMC

uft

Figura 1 - Integrantes das equipes finalistas descrevem como se sentem diante da expectativa pelo anúncio da região vitoriosa, no $13^{\circ}$ episódio de Cook Off

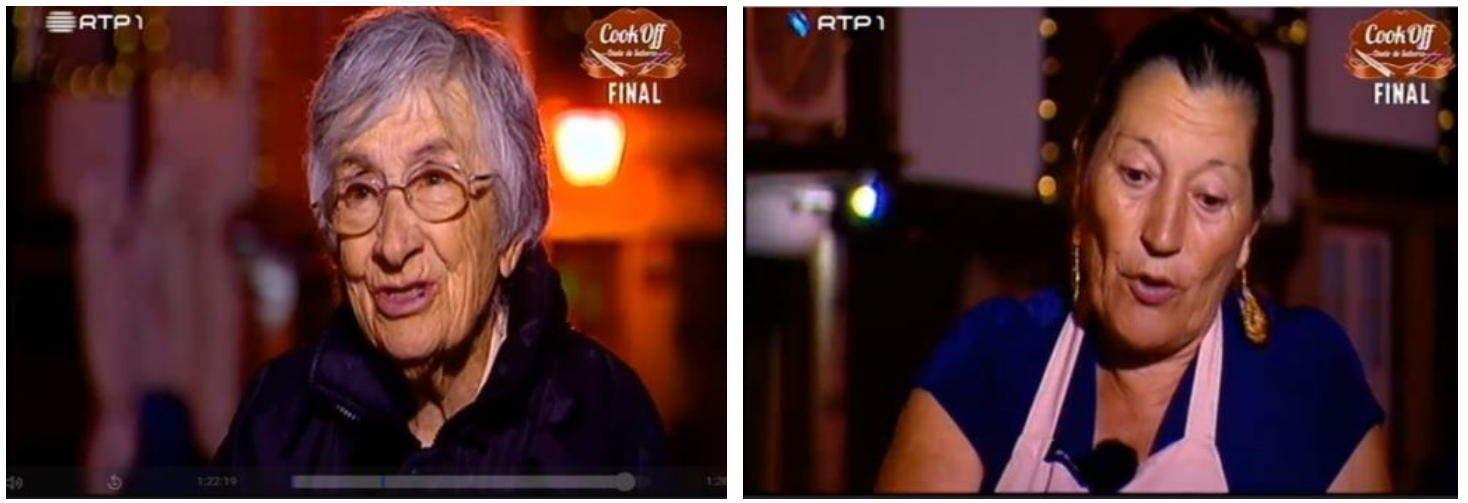

Fonte: Capturas de tela realizadas pela autora/RTP Play.

A edição assegura a inserção de tais depoimentos em diferentes situações, de modo que, embora o teor das falas seja muitas vezes repetitivo ou apenas reforce elementos que podem ser percebidos pelas imagens ou deduzidos pelo contexto, a redundância de sua presença confere um ar de "ao vivo" ao programa. Da mesma forma, a dramatização de emoções no decorrer da narrativa de Cook Off (ver Figura 2) constitui outro aspecto estilístico típico do reality show: uma vez que as personagens representam a si mesmas, trata-se de um dado que contribui, uma vez mais, ao efeito de realidade de que se reveste toda a produção.

Figura 2 - $13^{\circ}$ episódio de Cook Off: integrantes de uma das equipes finalistas mostram-se tensos no momento em que os jurados avaliam os pratos elaborados

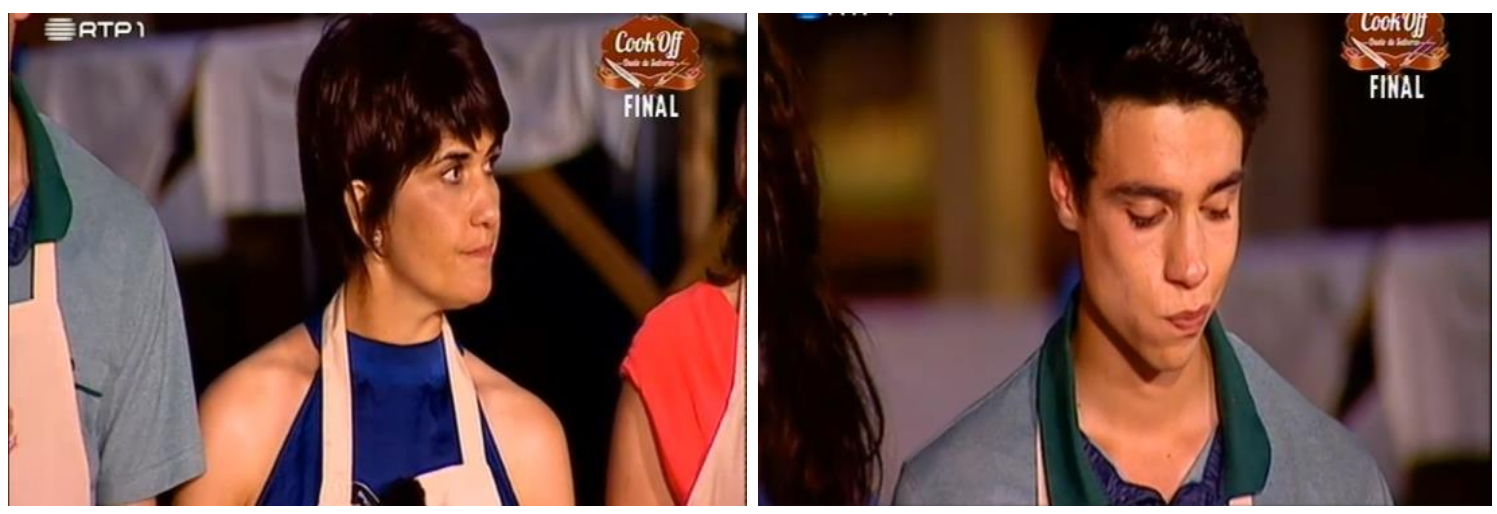

Fonte: Capturas de tela realizadas pela autora/RTP Play. 
Não obstante, ao lado de construções imagéticas tão comuns em reality shows culinários/gastronômicos, acreditamos ser possível vislumbrar, em Cook Off, elementos que tensionam articulações discursivas amplamente exploradas no gênero em questão. Uma das formas mais evidentes de materialização de tais pontos de afastamento diz respeito aos sentidos e valores atribuídos à temática da competição. Em especial, é possível observar um distanciamento em relação àquilo que Silvia Viana (2012) aponta como conversão dos realities em "rituais de sofrimento" por meio da valorização de uma concorrência exacerbada entre participantes, que são submetidos a provas em situações de forte estresse (muitas das quais envolvendo sofrimento físico, além do psicológico) como forma de alcançar a vitória ou evitar a eliminação.

As reflexões da autora apontam para a compreensão desse tipo de produção televisiva como exemplar da ênfase psicológica no sacrifício decorrente da universalização da cultura do trabalho, da qual faz parte "a demonstração permanente de um estado de engajamento, competitividade, disponibilidade, uma espécie de ousadia ativa temperada com doses importantes de submissão constitutiva" (VIANA, 2012, p. $175)^{11}$. Assim, o reality show operaria como uma espécie de "treinamento psíquico":

Dentro dele, o indivíduo se sacrifica para mostrar que pode... estar no reality show, enquanto que, fora dele, o indivíduo se sacrifica para compor socialmente o grande e opulento ritual de manutenção arbitrária da privação material e reprodução ad aeternum do sacrifício (VIANA, 2012, p. 177).

Em Cook Off, o tensionamento estabelecido em relação a tais modos de posicionar a temática da competição parece ser assumido como objetivo da produção do programa: segundo a sinopse presente no site da RTP, por exemplo, os "embates" apresentados ao longo dos episódios fariam parte de uma "saudável competição gastronómica" (RTP, s./d., online). Para além dessa declaração de intenções, chama a atenção, na construção dos episódios, a ausência de manifestações de hostilidade tão comuns em realities culinários/gastronômicos, como Master Chef e Kitchen's Hell.

\footnotetext{
11 Perspectiva similar é desenvolvida por Lage e Vaz (2019), que entendem os reality shows de sobrevivência como dispositivos produtores de modos de subjetivação, nos quais ocorre uma "produção estética" da figura do sobrevivente, orientada por uma lógica neoliberal voltada à produção de indivíduos empreendedores de si.
} 


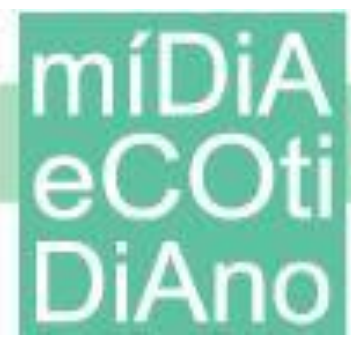

Quando os chefs avaliam os competidores, a posição assumida é mais próxima à de um professor do que à de um juiz ou censor, inclusive quando algum equívoco é cometido. É o que ocorre, por exemplo, no $11^{\circ}$ episódio - uma das semifinais de Cook Off, portanto, um momento de grande tensão -, quando o chef Kiko, ao avaliar o prato elaborado pela equipe do Alentejo, apresenta os problemas identificados de modo paciente e cordial: "Felipe, infelizmente, houve duas coisas que correram menos bem: a cozedura do peixe, nomeadamente o peixe que ainda tinha as escamas, e, sabes muito bem, a batata ainda estava encruada". Em geral, a postura é de acolhimento e compreensão, tanto entre equipes quanto entre chefs e participantes ${ }^{12}$.

No mesmo sentido, é possível destacar a presença de elementos que contribuem a uma atenuação dos sentidos de competitividade e concorrência no programa, como a solidariedade entre participantes, a alegria e o amor pela comida, o caráter amistoso dos encontros entre chefs e cozinheiros amadores locais - todos aspectos que evidenciam, novamente, o diálogo estabelecido com representações de uma cozinha como culinária. São diversos os momentos em que tais elementos se materializam, mas um dos mais marcantes se encontra no início do $1^{\circ}$ episódio, quando chef Kiko vai a Alcácer do Sal, no Alentejo, para compor uma equipe de cozinheiros locais. Os moradores oferecem ao chef pratos elaborados em suas casas, muitos deles a partir de tradições familiares. Após apresentar sua receita, que descreve como "borrego estufado à minha maneira", Maria Falcão, de 52 anos, dirige-se ao espectador: "Eu adoro cozinhar. Eu, quando estou a cozinhar, eu beijo os alimentos, eu brinco com eles, eu danço na cozinha”.

Ainda no mesmo episódio, merece destaque a afetuosidade presente no encontro entre chef Kiko e Maria Virgínia, de 69 anos, conhecida como "Maria Malcriada". Ele conhece a casa simples da moradora de Alcácer do Sal, que conta sobre sua vida, a criação dos filhos, o casamento e a viuvez. Após o encontro, dirigindo-se ao espectador, o chef expressa seu reconhecimento pela cozinheira e explica por que a escolheria para sua equipe: “Alguém que é mãe de quatro filhos é alguém que teve que alimentar quatro

\footnotetext{
12 Esses aspectos de "abrandamento" da competição aproximam Cook Off de características que Abdala e Andacht (2019) identificam no game show, tipologia que não raro se hibridiza ao reality show. Geralmente concebidos a partir de formatos comercializados em diferentes países, os game shows são programas que misturam competição ao entretenimento e geralmente possuem prescrições gerais que definem as regras das disputas entre participantes (ROCHA, 2009).
} 
bocas, sabe fazer render o peixe, sabe cozinhar, sabe transmitir o amor e o carinho através da comida, e eu vou aprender muito com ela, tenho certeza".

Mais à frente, o sentido de solidariedade comparece no primeiro duelo entre equipes competidoras representado no programa: aos 57 minutos do $1^{\circ}$ episódio, Felipe Cardoso, integrante da equipe de Reguengos de Monsaraz, tem dificuldades para manipular um equipamento eletroeletrônico referido como "varinha mágica” (um mixer) durante a prova. Ele é, então, ajudado por chef Kiko, que lidera a equipe rival. "Tem que ter fair-play, não é? E por isso tem que ajudar ambas as equipes", diz o chef, olhando diretamente para a câmera Poucos segundos depois, chef Cordeiro - descrito como mais rigoroso ou "implacável” do que seu colega - oferece ajuda a Júlio, da equipe de Alcácer do Sal, orientando-o sobre o jeito adequado de fatiar cebolas.

Evidentemente, quando as equipes de diferentes regiões de Portugal se enfrentam, há graus variáveis de tensão e estresse, explorados por meio de recursos de montagem que valorizam a dramatização, como já procuramos apontar; no entanto, a competição não se apresenta como fim em si mesma ou desafio necessário para alcançar a vitória individual ou evitar a eliminação: ela é representada como percurso a partir do qual se torna possível o (re)conhecimento de sabores locais. Em outras palavras, a competição é integrada a uma narrativa de celebração da diversidade das cozinhas regionais portuguesas, na qual se medeiam sentidos de pertencimento a uma identidade nacional. Não à toa, a sonoplastia dos momentos em que ocorrem os duelos culinários é marcada por trilhas que, somadas aos elementos visuais, sugerem sentidos marcadamente épicos, não raro fazendo lembrar a cobertura televisiva de grandes competições esportivas.

Isso fica evidente, na construção da narrativa do programa, pela priorização da descoberta de sabores locais e tradicionais em detrimento dos espaços de competição entre participantes. Essa tendência se apresenta principalmente nos dez primeiros episódios ${ }^{13}$,

\footnotetext{
${ }^{13}$ Os episódios 1 a 10 correspondem à primeira fase de Cook Off e mostram os chefs Kiko e Cordeiro visitando diferentes regiões de Portugal. A cada região, cada chef escolhe uma cidade ou localidade onde procurará cozinheiros amadores talentosos para compor uma equipe. Os profissionais experimentam receitas caseiras e ouvem histórias dos moradores. Essa dinâmica ocupa a maior parte dos episódios nessa primeira etapa do programa; geralmente, diante de algum impasse na definição dos integrantes das equipes, os chefs propõem desafios entre os moradores de cada cidade para, dessa forma, definirem sua escolha. Além disso, a parte final dos episódios é destinada a uma prova em que se enfrentam as equipes formadas pelos dois chefs. Já nos episódios 11 e 12 (semifinais) e 13 (final), as provas e desafios ocupam a quase totalidade do tempo de programa.
} 


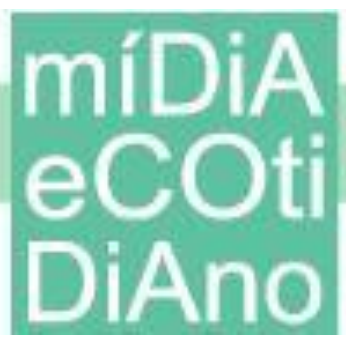

nos quais a maior parte do tempo é reservada ao encontro entre chefs e moradores das diferentes regiões visitadas. Outro dado que se destaca é a constante reafirmação do papel desempenhado pelo resgate de um saber-fazer cotidiano como objetivo da viagem empreendida pelos chefs por Portugal, sentido que dialoga com representações da cozinha como culinária. Já no $1^{\text {o }}$ episódio, por exemplo, ao aproximar-se da cidade de Reguengos de Monsaraz, o chef Cordeiro afirma: "Vamos ver se consigo preparar aqui algumas receitas antigas, pratos que estão em desuso e joias da gastronomia popular".

A todo momento, evidenciam-se sentimentos de pertencimento e orientação para a coletividade como fatores que motivam a ação dos personagens. Antes de ter início o duelo que ocupa a última parte do $1^{\circ}$ episódio, integrantes das equipes fazem declarações como "Eu me sinto muito bem em estar aqui em Estremoz a representar Alcácer do Sal" e "Eu sinto-me orgulhoso de estar a representar Reguengos, uma vez que é a minha cidade". Pouco depois, assim que a prova começa, a montagem coloca em destaque uma fala de José Galhardo, competidor da equipe de Reguengos de Monsaraz: “A nossa estratégia é uma equipe, é jogar por equipe, e quando um estiver mais livre vai ajudar o outro". Assim, ao mesmo tempo em que coloca em cena a rivalidade entre cidades/regiões, o programa reforça a solidariedade existente em cada grupo. Da mesma forma, quase ao final da prova, chef Kiko destaca o caráter amistoso da interação entre equipes e ressalta, como motivação que se sobrepõe a interesses particulares, os vínculos que os cozinheiros mantêm com sua região: "Eu acho que a relação entre as duas equipas foi uma relação boa, foi uma relação de fair-play, de amizade, porque aquilo que eles pretendem no fundo é que o Alentejo esteja bem representado na final”.

Os aspectos descritos sinalizam alguns dos principais pontos de tensionamento que se apresentam em Cook Off - Duelo de Sabores em relação a visibilidades hegemônicas em reality shows atuais, especialmente em sua vertente culinária/gastronômica. Assim, ao lado do deslocamento da valorização ético-estética do sofrimento, da competitividade e da eliminação, a produção em foco tensiona também os papéis comumente desempenhados pela comida e pelo saber-fazer culinário nessas produções. Sobre este último aspecto, Rezende e Lavinas (2017) chamam a atenção para o fato de que, em reality shows de competição na cozinha, "a propagação do saber culinário situa-se em um plano secundário em relação à dinâmica do jogo e da 


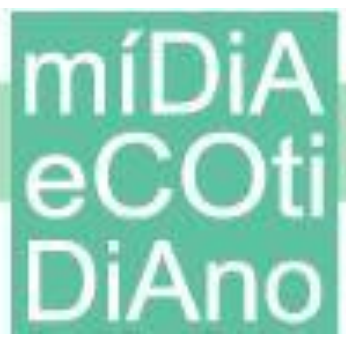

eliminação" (REZENDE; LAVINAS, 2017, p. 83). Já em Cook Off, a comida, o cozinhar e as relações em torno do saber-fazer culinário ocupam lugar prioritário entre as visualidades produzidas e na arquitetura narrativa dos episódios, mediando aspectos identitários/afetivos e visibilidades locais/regionais, cujo (re)conhecimento pelos chefs e apresentação ao público constituem o grande mote da produção.

\section{Negociações entre sentidos de culinária e gastronomia}

Para compreender como se dão as negociações em torno de sentidos de cozinha como culinária e de cozinha como gastronomia em Cook Off, é preciso visualizar como as duas representações da cozinha são mobilizadas e atualizadas ao longo da estrutura narrativa do programa, inscrevendo-se na materialidade de suas audiovisualidades. Indo além, esses dois regimes representacionais moldam-se e delimitam-se mutuamente, de modo que um só pode fazer sentido em face do outro. Como veremos, esse diálogo é um elemento-chave à construção dos sentidos globais da produção.

Sentidos de cozinha como gastronomia ganham espaço nos últimos episódios da produção (mais especificamente, nos capítulos 11 a 13). Os episódios 11 e 12 correspondem às semifinais da competição entre equipes de diferentes regiões de Portugal; em cada semifinal, cinco equipes realizam desafios específicos, que envolvem desde a replicação de uma receita preparada pelos chefs Kiko e Cordeiro quanto a releitura criativa de receitas tradicionais. Duas equipes são selecionadas para a final, que acontece no $13^{\circ}$ episódio, em Guimarães, cidade cuja escolha não é ocasional: considerada o berço de Portugal, a localidade encarna o ideal da nação em que se coadunam identidades regionais.

Assim, no último episódio, as equipes representantes das regiões das Beiras e do Minho enfrentaram-se em duas provas: na primeira, cada time deveria elaborar um prato típico da região adversária; na segunda, os cozinheiros amadores precisaram elaborar criativamente, com base em técnicas diversificadas, um prato que utilizasse um ingrediente-surpresa típico de cada região (perdiz, no caso das Beiras, e bochecha de porco, no caso do Minho). Na final e nas semifinais, colocam-se novas questões para os participantes, como a preocupação com a estética e o empratamento das receitas.

Os três últimos episódios, embora visibilizem elementos característicos de uma cozinha gastronomizada - como a criatividade, a autoria, a sofisticação, a distinção 


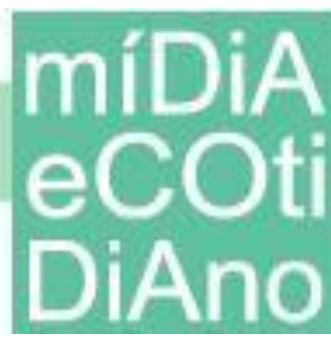

estética etc. -, não deixam de mobilizar sentidos de uma cozinha como culinária. Isso fica evidente no sentimento de desconforto que se inscreve nas imagens do programa, que mostram cozinheiros amadores, muitos deles habituados à vida em pequenas aldeias, pouco à vontade diante de aparatos complicados e instrumentos desconhecidos da cozinha cotidiana. Da mesma forma, há uma clara hierarquia entre diferentes regimes representacionais da cozinha, na qual sentidos de cozinha como culinária subordinam-se a sentidos de uma cozinha como gastronomia. É o que mostra, por exemplo, a forma como os participantes apresentam visualmente as receitas: artificiais e disformes, como os traçados inseguros de uma criança que ainda aprende a desenhar, as imagens dos empratamentos sintetizam exemplarmente as tensões do encontro entre culinária e gastronomia encenado no programa (Figura 3).

Figura 3 - Empratamentos apresentados pela equipe do Alentejo, no $11^{\circ}$ episódio (à esq.), e pela equipe das Beiras, no $13^{\circ}$ episódio (à dir.)
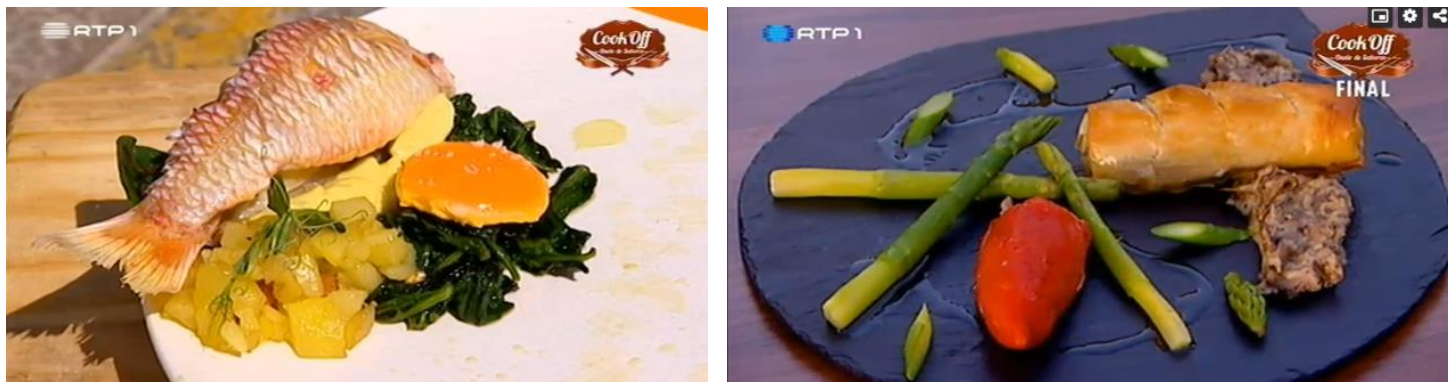

Fonte: Capturas de tela realizadas pela autora/RTP Play.

No entanto, mesmo nos episódios finais, os chefs expressam seu reconhecimento pelos saberes da cozinha cotidiana. É importante observar que isso ocorre não exatamente "apesar" da clara demarcação de hierarquia entre regimes representacionais da cozinha, mas precisamente em função dela: afinal, os chefs só podem reconhecer o valor da cozinha como culinária porque se encontram em uma posição que lhes confere autoridade para tanto. Assim, nos minutos finais do $13^{\circ}$ episódio, chef Kiko faz uma fala que, assumindo ares de "conclusão" do programa, sintetiza muitos dos sentidos de cozinha como culinária como representados na produção: “[...] acho que a verdadeira razão de eu ser cozinheiro é dar alegria às pessoas. Mexer com as pessoas, entusiasmar as pessoas, vibrar, colocar as pessoas a viajar”. A apresentadora Catarina Furtada complementa o 


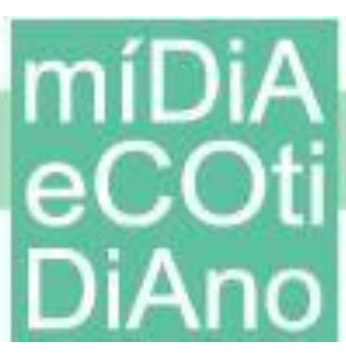

raciocínio: "De fato, uma das coisas que aprendemos com o Cook Offé que a gastronomia é feita por pessoas que trazem as suas vidas consigo e põem muito do que é sua vida no prato".

Se os três últimos episódios representam uma ampliação da presença de referências a uma cozinha gastronomizada no programa, os dez primeiros revelam a primazia de sentidos de cozinha como culinária por meio de representações de uma cozinha cotidiana, popular, tradicional, local/regional, familiar. O olhar que nos conduz nessa descoberta, como sabemos, é o olhar dos chefs, que avaliam a qualidade de pratos elaborados por cozinheiros amadores, e as imagens da cozinha como culinária parecem manifestar-se em três eixos principais.

Em primeiro lugar, destaca-se a imagem da casa como guardiã de saberes culinários: nesses espaços domésticos, comidas simples emergem trivial e alheiamente aos arranjos espetaculares próprios de visualidades da comida como gastronomia. Nos episódios, os pratos que os cozinheiros locais preparam para a apreciação dos chefs são feitos em suas casas; de lá, saem à rua em tigelas desgastadas, potes de plástico, sacolas e cestas de compras (ver Figura 4).

Em segundo lugar, temos as imagens da rua como espaço de sociabilidade. De fato, o espaço da praça pública é constantemente visibilizado na produção: é nela que os cozinheiros amadores apresentam seus pratos aos chefs, na primeira parte dos dez primeiros capítulos (ver Figura 5), e é também na rua que acontecem todos os duelos entre equipes de diferentes cidades/regiões. Espaço de encontro e congregação, a rua é também o espaço de partilha do alimento: se a comida nasce na domesticidade da casa, é na praça que ela encontra seu destino.

Ao mesmo tempo, a relação com a comida mediada pela espacialidade do convívio encontra eco em relatos de vivências comunitárias e/ou solidárias apresentados em diversos momentos no programa. É o caso da participante Josefina Pissara, de 80 anos, que surge no $2^{\circ}$ episódio; ao apresentar seu prato ao chef Cordeiro, ela fala sobre a convivência com as pessoas de sua aldeia e as amizades que construiu ao longo da vida, destacando o fato de os vizinhos cuidarem uns dos outros, de as pessoas "preocuparemse umas com as outras". 


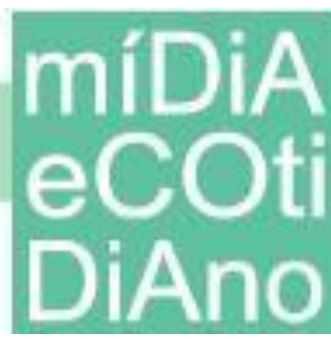

\section{PPGMC}

uff

Figura 4 - Maria Letra, participante da cidade de Alcácer do Sal, apresenta seus pratos no $1^{0}$ episódio

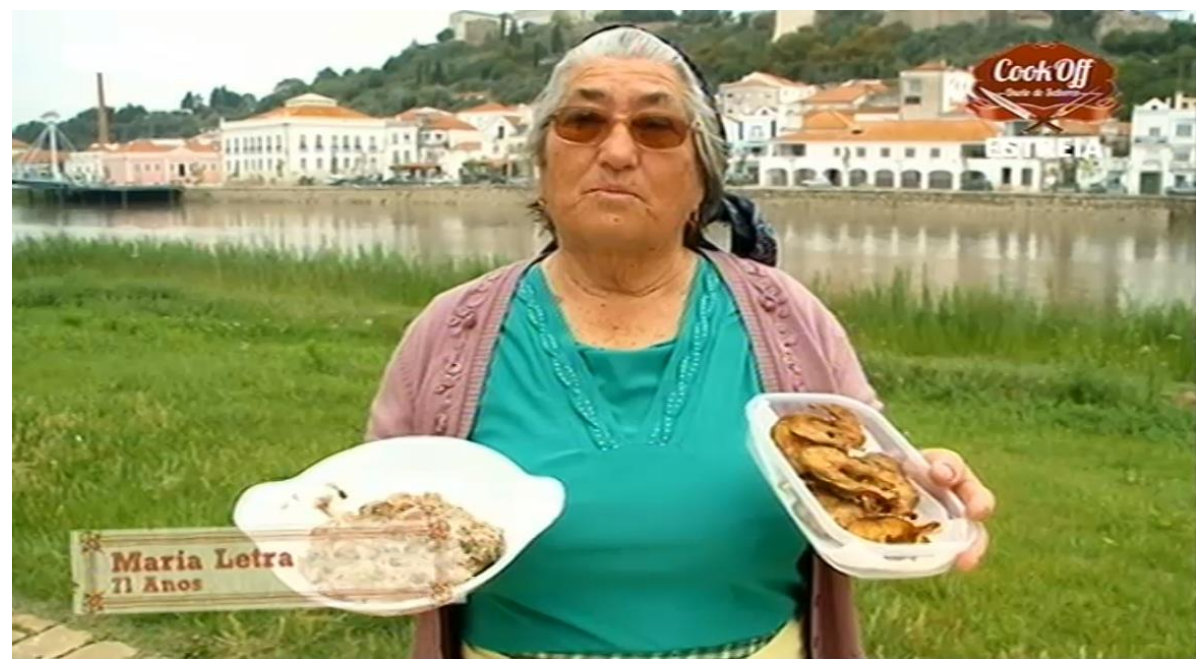

Fonte: Captura de tela realizada pela autora/RTP Play.

Figura 5 - Participantes de Alcácer do Sal reunidos na rua para apresentar seus pratos no $1^{\circ}$ episódio

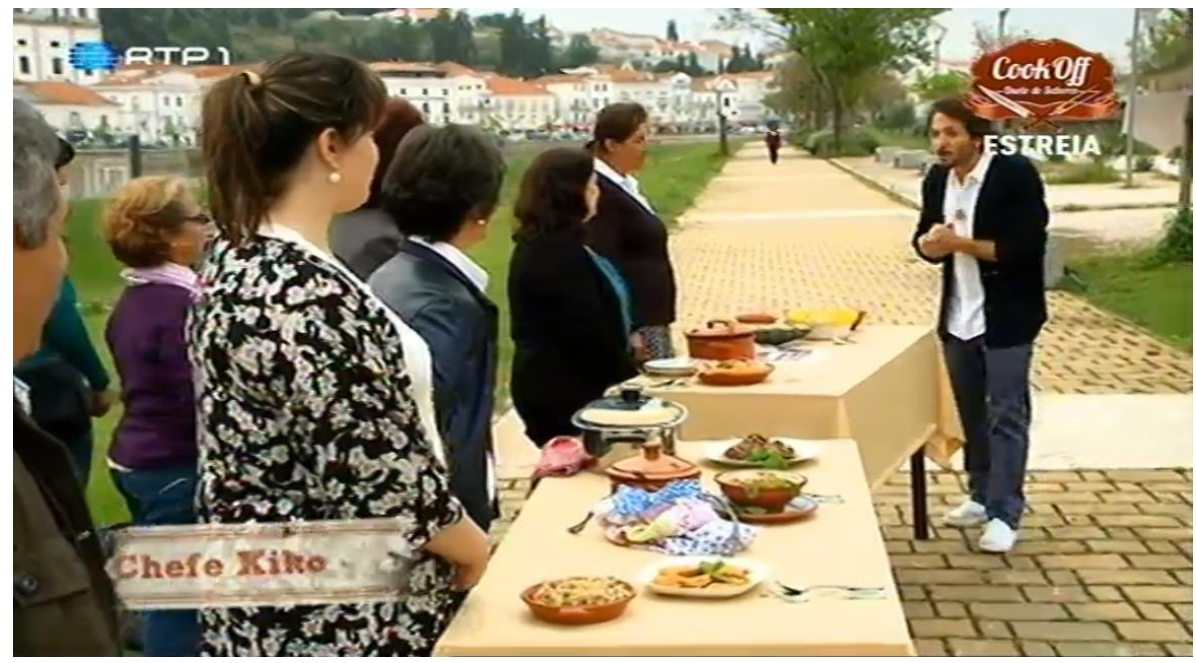

Fonte: Captura de tela realizada pela autora/RTP Play.

Em terceiro lugar, destacam-se imagens da cozinha como local de experimentação de afetividades: em torno das panelas, vive, pulsante, não apenas o amor à boa mesa, mas diversos afetos mediados pela comida. É na cozinha de Maria Malcriada, por exemplo, que um dos encontros mais afetivos do programa se realiza, já no $1^{\circ}$ episódio (ver Figura 6). 
Figura 6 - Chef Kiko na cozinha da casa de Maria Malcriada, no $1^{\circ}$ episódio

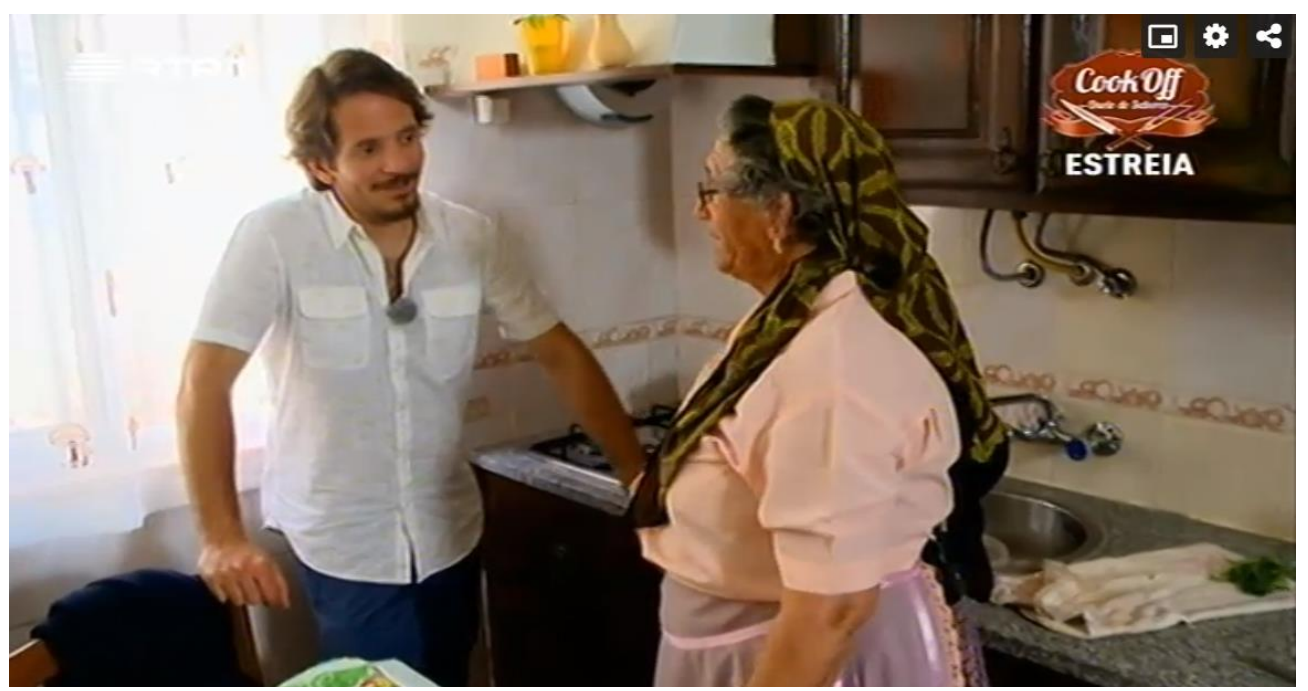

Fonte: Captura de tela realizada pela autora/RTP Play.

Da mesma forma, depoimentos de participantes e afirmações dos chefs dão conta da cozinha como forma de amar, como já procuramos assinalar. Indo além, a cozinha como espaço mediador de laços afetivos parece transbordar para todos os espaços do programa, já que muitas das relações representadas - como aquela entre chef Kiko e a participante Josefina Pissara - são revestidas de ternura e afeição, sentimentos que se manifestam inclusive durante as provas.

Como as imagens destacadas evidenciam, os sentidos de cozinha como culinária em Cook Off assumem os contornos de uma cozinha cotidiana e popular ${ }^{14}$. São imagens que asseguram o distanciamento em relação à tendência à estetização da comida que, potencializada por elementos de sofisticação e distinção, prevalece em reality shows culinários/gastronômicos (REZENDE; LAVINAS, 2017). Além disso, narrativamente, esse dado contribui para uma organização interna que afasta a produção dos rituais de

\footnotetext{
${ }^{14}$ Evidentemente, algumas estratégias por meio da quais as representações do popular são integradas aos enunciados do programa podem ser problematizadas. Em especial, chamamos a atenção para o fato de que a visibilização das cozinhas regionais tradicionais, cuja síntese se apresenta como signo da cozinha nacional portuguesa, parece aproximar-se em alguns momentos de uma concepção essencializada do popular. Trata-se de uma visão que reflete o próprio resgate e valorização das cozinhas regionais no século XX em Portugal, processo que ocorreu sob forte influência de valores nacionalistas e levou à consagração e prestígio da cozinha portuguesa (SOBRAL, 2007). Erigido sobre pertenças de sangue e território, esse sentido de popular, não distante de uma visão romântica sobre o tema, como a descreve Martín-Barbero (2003), minimiza o papel das disputas inerentes à própria cozinha e à cultura populares.
} 


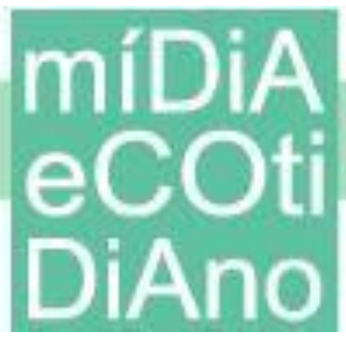

sofrimento (VIANA, 2012) comuns em realities dedicados ao universo da cozinha (como Master Chef e Kitchen's Hell).

Dessa forma, ainda que mediadas por sentidos de cozinha como gastronomia, imagens e vozes de uma cotidianidade culinária popular, que dão a ver astúcias criativas e microrresistências próprias do cotidiano (CERTEAU, 1994), emergem como formas residuais do popular no massivo (MARTÍN-BARBERO, 2003). Assim, ao considerar as negociações estabelecidas em Cook Off entre regimes representacionais da cozinha, devemos ter em mente, como ensina Carlo Ginzburg (1996), que o popular - seja em sua acepção geral, seja em experiências históricas especificas - só pode ser entendido em relação ao hegemônico, na trama da circularidade entre referências culturais.

\section{Considerações finais}

Ao longo do percurso analítico do artigo, procuramos evidenciar de que maneiras o programa Cook Off - Duelo de Sabores, exibido em 2015 pela rede televisiva portuguesa RTP1, caracteriza-se por uma série de negociações em torno das mediações características de reality shows televisivos, sobretudo em sua vertente culinária/gastronômica.

Como vimos, a produção mobiliza, por um lado, aspectos típicos desse tipo de produção, sobretudo no que diz respeito às marcas estilísticas de uma busca por "referencialização" própria do reality show. Por outro lado, um exame mais aprofundado do programa revela também, se não verdadeiras rupturas, ao menos tensionamentos em relação às visibilidades hegemônicas do gênero - tensionamentos esses que dizem respeito tanto à representação da temática da competição e seu desenvolvimento narrativo quanto aos sentidos de cozinha engendrados na produção.

Ao mesmo tempo, buscamos cotejar a hipótese de que o diálogo com/entre diferentes sentidos em circulação acerca da cozinha e suas práticas é constitutivo da própria textualidade audiovisual. Nesse sentido, um aspecto fundamental à compreensão das negociações estabelecidas em relação às visibilidades comumente engendradas em reality shows diz respeito às formas como, em Cook Off, são propostos diálogos entre o que temos denominado como sentidos de "cozinha como gastronomia" e sentidos de "cozinha como culinária". 
Em especial, destacamos as representações desta última, as quais se articulam por meio de vozes e imagens de uma cozinha cotidiana e popular. Entendemos que este constitui um ponto de distinção fundamental de Cook Off em relação à maioria dos reality shows de competição gastronômica, já que, nestas produções, predominam sentidos de uma cozinha gastronomizada, o que é intensificado pela presença de signos de alta competitividade, eliminação, produtivismo etc. Se não ausentes de Cook Off - Duelo de Sabores, tais representações têm seu poder de refração redimensionado em face de uma narrativa que privilegia refrações outras.

Dessa forma, em imagens próprias de um regime representacional da cozinha como culinária que emerge em Cook Off, deixam-se entrever (à revelia?) “artes de fazer" (CERTEAU, 1994) presentes no saber-fazer culinário do dia a dia. Talvez seja justamente nestas ínfimas brechas da representação que o programa desafie, de maneira mais decisiva, as visualidades hegemonicamente engendradas em reality shows de culinária/gastronomia.

\section{Referências}

ABDALA, Karina; ANDACHT, Fernando. Representações culturais no reality show gastronômico. Comunicação, Mídia e Consumo, São Paulo, v. 16, n. 46, p. 226-251, mai./ago. 2019. Disponível em: http://revistacmc.espm.br/index.php/revistacmc/article/view/1984/pdf. Acesso em: 27 jan. 2021.

BAKHTIN, Mikhail. Os gêneros do discurso. Trad. Paulo Bezerra. São Paulo: Editora 34, 2016.

BARROS, Diana L. P. "Dialogismo, polifonia e enunciação”. In: BARROS, Diana L. P.; FIORIN, José Luiz (Orgs.). Dialogismo, polifonia, intertextualidade. São Paulo: Editora da Universidade de São Paulo, 2003, p. 1-9.

CERTEAU, Michel de. A invenção do cotidiano: 1. Artes de fazer. Petrópolis: Vozes, 1994.

COSTA, Raquel. Audiências 2015: quem ganhou e quem perdeu. Diário de Notícias, 02/01/2016. Disponível em: https://www.dn.pt/media/audiencias-2015-quem-ganhou-e-quemperdeu-4961462.html. Acesso em: 27 jan. 2021.

FERREIRA, David. Final de "Cook Off - Duelo de Sabores" vista por 445 mil, A Televisão, 28/09/2015. Disponível em: https://www.atelevisao.com/rtp/final-de-cook-off-duelo-desabores-vista-por-445-mil/. Acesso em: 27 jan. 2021. 
FILIPE, Marco. “Cook Off” tem melhor resultado e "Ídolos" pior. Diário da TV, 01/06/2015. Disponível em: https://diario-da-tv.blogspot.com/2015/06/cook-off-tem-melhor-resultado-eidolos.htm. Acesso em: 27 jan. 2021.

GINZBURG, Carlo. O queijo e os vermes: o cotidiano e as idéias de um moleiro perseguido pela Inquisição. São Paulo: Companhia das Letras, 1996.

HILL, Annette. Reality TV: audiences and popular factual television. Londres: Routledge, 2007.

JACOB, Helena. "Gastronomídia: os ambientes midiáticos e as linguagens da comida e da cozinha”. Communicare, v. 12, n. 2, jul./dez. 2012, p. 113-125. Disponível em: https://casperlibero.edu.br/wp-content/uploads/2014/01/Gastronom\%C3\%ADdia-os-ambientesmidi\%C3\%A1ticos-e-as-linguagens-da-comida-e-da-cozinha.pdf. Acesso em: 27 jan. 2021.

JOST, François. Compreender a televisão. Porto Alegre: Sulina, 2007.

LAGE, Leandro Rodrigues; VAZ, Paulo Roberto Gibaldi. Moralidade sobrevivente em "Largados e Pelados": do espetáculo televisivo à produção do indivíduo empreendedor de si. In: XXVIII Encontro Nacional dos Programas de Pós-Graduação em Comunicação, 2019, Porto Alegre. Anais... Brasília: Compós, 2019. Disponível em: http://revistacmc.espm.br/index.php/revistacmc/article/view/1984/pdf. Acesso em: 27 jan. 2021.

KEANE, M; MORAN, A. Television's New Engines. Television New Media, v. 9, n. 2, 2008.

MARTA, Pedro. RTP1 suspende "Cook Off - Duelo de Sabores" durante o verão. Zapping TV, 23/07/2015. Disponível em: https://www.zapping-tv.com/rtp1-suspende-cook-off-duelo-desabores-durante-o-verao/. Acesso em: 27 jan. 2021.

MARTÍN-BARBERO, Jesús. Dos meios às mediações: comunicação, cultura e hegemonia. Trad. Ronald Polito e Sérgio Alcides. Rio de Janeiro: Editora UFRJ, 2003.

OLIVEIRA, Caroline Cavalcante. "Das concepções e representações do gosto pela mídia: reflexões acerca da imagem estetizada da comida na divulgação de receitas culinárias”. Culturas Midiáticas, ano IX, n. 15, p. 136-150, jan./jun. 2016. Disponível em: https://periodicos.ufpb.br/ojs2/index.php/cm/article/view/29367. Acesso em: 27 jan. 2021

REZENDE, Renata; LAVINAS. Gastronomia midiática: reality shows e a estetização da comida na TV. Lumina, Juiz de Fora, v. 11, n. 3, p. 75-94, set./dez. 2017. Disponível em: https://periodicos.ufjf.br/index.php/lumina/article/view/21240/11550. Acesso em: 27 jan. 2021.

ROCHA, Debora Cristine. Reality TV e reality show: ficção e realidade na televisão. ECompós, Brasília, v. 12, n. 3, set./dez. 2009. Disponível em: https://doi.org/10.30962/ec.387. Acesso em: 27 jan. 2021.

RTP. Cook Off - Duelo de Sabores. Disponível em: https://media.rtp.pt/cookoff/. Acesso em: 27 jan. 2021.

SOBRAL, José Manuel. Nacionalismo, culinária e classe: a cozinha portuguesa da obscuridade à consagração (séculos XIX-XX). RURIS, Campinas, v. 1, n. 2, p. 13-52, set. 2007. Disponível em: https://www.ifch.unicamp.br/ojs/index.php/ruris/article/view/651/518. Acesso em: 27 jan. 2021. 
SOUZA, José Carlos Aronchi de. Gêneros e Formatos na Televisão Brasileira. São Paulo: Summus, 2004.

STYCER, Maurício. Seis motivos que explicam o sucesso das competições de culinária na TV. Uol, 20/10/2019. Disponível em:

https://tvefamosos.uol.com.br/blog/mauriciostycer/2019/10/20/seis-motivos-que-explicam-osucesso-das-competicoes-de-culinaria-na-tv. Acesso em: 27 jan. 2021.

VIANA, Silvia. Rituais de sofrimento. São Paulo: Boitempo, 2012.

VOLÓCHINOV, Valentin. (Círculo de Bakhtin). Marxismo e filosofia da linguagem: problemas fundamentais do método sociológico na ciência da linguagem. Trad. Sheila Grillo e Ekaterina Vólkova Américo. São Paulo: Editora 34, 2017. 